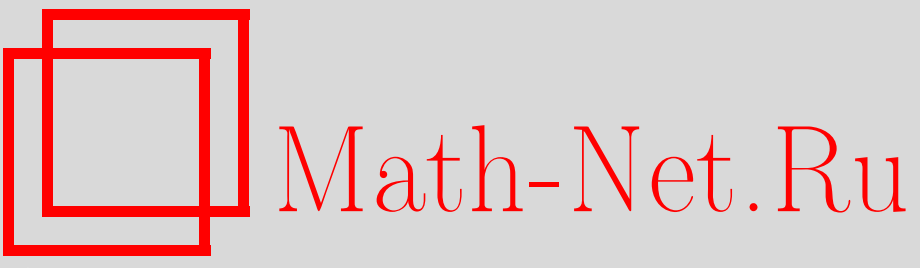

V. P. Maksimov, On a class of linear continuous-discrete systems with discrete memory, Vestn. Udmurtsk. Univ. Mat. Mekh. Komp. Nauki, 2020, Volume 30, Issue 3, 385-395

DOI: https://doi.org/10.35634/vm200303

Use of the all-Russian mathematical portal Math-Net.Ru implies that you have read and agreed to these terms of use

http://www.mathnet.ru/eng/agreement

Download details:

IP : 35.173 .137 .237

April 26, 2023, 08:37:31 
MSC2010: 34K10, 34K30, 34K35, 91B74

\author{
(C) V.P. Maksimov
}

\title{
ON A CLASS OF LINEAR CONTINUOUS-DISCRETE SYSTEMS WITH DISCRETE MEMORY
}

A class of linear functional differential systems with continuous and discrete times and discrete memory is considered. An explicit representation of the principal components to the general solution representation such as the fundamental matrix and the Cauchy operator is derived. The obtained representation is given in terms of the system parameters and opens a way towards efficient studying general linear boundary value problems and control problems with respect to a fixed collection of linear on-target functionals. In the study of the problems mentioned above outside the class under consideration, the systems with discrete memory can be employed as model or approximating ones. This can be useful as applied to systems with aftereffect under studying rough properties that hold under small perturbations of the parameters.

Keywords: linear systems with delay, functional differential systems with continuous and discrete times, representation of solutions, Cauchy operator.

DOI: $10.35634 / \mathrm{vm} 200303$

\section{Introduction}

Here we continue the study of linear continuous-discrete systems with aftereffect in the frame of an approach developed in the previous works [3, 5, 6, 8]. For a class of linear systems with continuous and discrete times and discrete memory, we derive an explicit representation of the principal components to the general solution representation such as the fundamental matrix and the Cauchy operator. The obtained representation opens a way towards efficient studying general linear boundary value problems and control problems with respect to a fixed collection of ontarget functionals [3]. In the study of the problems mentioned above outside the class under consideration, the systems can be employed as model or approximating ones. It can be useful under studying rough properties that hold under small perturbances of the parameters, see, for instance, [7] and references therein.

The system under consideration includes two types of variables simultaneously, namely, the state variables depending on the continuous time, $t \in[0, T]$, and the variables with dependence on the discrete time, $t \in\left\{0, t_{1}, \ldots, t_{\mu}\right\}$. As for the term "continuous-discrete systems", we follow the author of $[1,2]$. It should be noted that, in the above works, the detailed motivation for the study of certain classes of continuous-discrete systems as well as some examples of the urgent applied problems such as stabilization, observability, and controllability problems are presented. For further results on the problems mentioned we refer to [10-12] and the references therein. A special feature of the systems under consideration is that the memory of the system operators is discrete and located at the points $t_{j}$ strictly preceding the current instant $t\left(t_{j}<t\right)$. Some applications of such systems in economic dynamics problems are presented in $[9,13]$.

\section{$\S 1$. The system description}

Let us introduce the Banach spaces where the operators and the equations are considered and describe the main subject. Fix a segment $[0, T] \subset R$. We denote by $L^{n}=L^{n}[0, T]$ the space of 
summable functions $v:[0, T] \rightarrow R^{n}$ with the norm $\|v\|_{L^{n}}=\int_{0}^{T}|v(s)|_{n} d s$, where $|\cdot|_{n}$ (or $|\cdot|$ for short if the dimension value is clear) stands for the norm in $R^{n} ; A C^{n}=A C^{n}[0, T]$ is the space of absolutely continuous functions $x:[0, T] \rightarrow R^{n}$ with the norm $\|x\|_{A C^{n}}=|x(0)|_{n}+\|\dot{x}\|_{L^{n}}$. Next we fix the set $J=\left\{t_{0}, t_{1}, \ldots, t_{\mu}\right\}, 0=t_{0}<t_{1}<\ldots<t_{\mu}=T$. Let $F D^{\nu}(\mu)=$ $=F D^{\nu}\left\{t_{0}, t_{1}, \ldots, t_{\mu}\right\}$ be the space of functions $z: J \rightarrow R^{\nu}$ under the norm

$$
\|z\|_{F D^{\nu}(\mu)}=\sum_{i=0}^{\mu}\left|z\left(t_{i}\right)\right|_{\nu} .
$$

We consider the system

$$
\begin{gathered}
\dot{x}(t)=\sum_{j: t_{j}<t} A_{j}(t) x\left(t_{j}\right)+\sum_{j: t_{j}<t} B_{j}(t) z\left(t_{j}\right)+f(t), \quad t \in[0, T], \\
z\left(t_{i}\right)=\sum_{j<i} D_{i j} x\left(t_{j}\right)+\sum_{j<i} H_{i j} z\left(t_{j}\right)+g\left(t_{i}\right), \quad i=1, \ldots, \mu .
\end{gathered}
$$

Here the columns of $(n \times n)$-matrices $A_{j}$ and $(n \times \nu)$-matrices $B_{j}$ belong to the space $L^{n}, f \in L^{n}$; $(\nu \times n)$-matrices $D_{i j}$ and $(\nu \times \nu)$-matrices $H_{i j}$ have constant elements, $g: J \rightarrow R^{\nu}$.

The system (1.1)-(1.2) is a special case of the general continuous-discrete system considered in detail in [8]. Theorem 1 [8] gives the representation of the general solution in the form

$$
\left(\begin{array}{l}
x \\
z
\end{array}\right)=\mathcal{Y}\left(\begin{array}{l}
x(0) \\
z(0)
\end{array}\right)+\mathcal{C}\left(\begin{array}{l}
f \\
g
\end{array}\right)
$$

where $z=\operatorname{col}\left(z\left(t_{1}\right), \ldots, z\left(t_{\mu}\right), g=\operatorname{col}\left(g\left(t_{1}\right), \ldots, g\left(t_{\mu}\right)\right.\right.$,

$$
\mathcal{Y}=\left(\begin{array}{ll}
\mathcal{Y}_{11} & \mathcal{Y}_{12} \\
\mathcal{Y}_{21} & \mathcal{Y}_{22}
\end{array}\right)
$$

is the fundamental matrix,

$$
\mathcal{C}=\left(\begin{array}{ll}
\mathcal{C}_{11} & \mathcal{C}_{12} \\
\mathcal{C}_{21} & \mathcal{C}_{22}
\end{array}\right)
$$

is the Cauchy operator. Here the block components $\mathcal{Y}_{i j}, \mathcal{C}_{i j}, i, j=1,2$, are operators acting as follows:

$$
\begin{aligned}
& \mathcal{Y}_{11}: R^{n} \rightarrow A C^{n} ; \quad \mathcal{Y}_{12}: R^{\nu} \rightarrow A C^{n} ; \quad \mathcal{Y}_{21}: R^{n} \rightarrow R^{\nu \mu} ; \quad \mathcal{Y}_{22}: R^{\nu} \rightarrow R^{\nu \mu} \\
& \mathcal{C}_{11}: L^{n} \rightarrow A C^{n} ; \quad \mathcal{C}_{12}: R^{\nu \mu} \rightarrow A C^{n} ; \quad \mathcal{C}_{21}: L^{n} \rightarrow R^{\nu \mu} ; \quad \mathcal{C}_{22}: R^{\nu \mu} \rightarrow R^{\nu \mu} .
\end{aligned}
$$

It should be noted that, with respect to the continuous time component $x(t)$, we restrict ourself to the case $x \in A C^{n}$ and so ignore the impulsive component of the solution [8].

Our aim is to give the explicit representation of $\mathcal{Y}$ and $\mathcal{C}$ in terms of the system matrix parameters.

\section{§2. The fundamental matrix and the Cauchy operator}

A principal point of the consideration is to obtain a linear algebraic system with respect to the vector $(\mathbf{x}, z)=\operatorname{col}\left(x\left(t_{1}\right), \ldots, x\left(t_{\mu}\right), z\left(t_{1}\right), \ldots, z\left(t_{\mu}\right)\right)$. The inverse to the matrix of the system will give the desired representation. In doing so we execute the following steps. 
1. Integrate the two sides of (1.1) from 0 to $t_{i}$.

$$
x\left(t_{i}\right)=x(0)+\sum_{j=0}^{\mu} \int_{0}^{t_{j}} A_{j}(s) \chi_{j}(s) d s x\left(t_{j}\right)+\sum_{j=0}^{\mu} \int_{0}^{t_{j}} B_{j}(s) \chi_{j}(s) d s z\left(t_{j}\right)+\int_{0}^{t_{i}} f(s) d s .
$$

Here $\chi_{j}(s)$ stands for the characteristic function of $\left(t_{j}, T\right]$.

2. In the sequel, it will be convenient to use the following notation.

$$
\begin{aligned}
x_{i}=x\left(t_{i}\right), \quad z_{i}=z\left(t_{i}\right), \quad \phi_{i}=\int_{0}^{t_{i}} f(s) d s, \quad \psi_{i}=g\left(t_{i}\right), \quad i=1, \ldots, \mu \\
\mathcal{A}_{i j}=\int_{0}^{t_{j}} A_{j}(s) \chi_{j}(s) d s \quad \text { if } j<i, \quad \mathcal{A}_{i j}=0 \quad \text { otherwise } \\
\mathcal{B}_{i j}=\int_{0}^{t_{j}} B_{j}(s) \chi_{j}(s) d s \quad \text { if } j<i, \quad \mathcal{B}_{i j}=0 \quad \text { otherwise; } \\
\mathcal{D}_{i j}=D_{i j} \quad \text { if } j<i, \quad \mathcal{D}_{i j}=0 \quad \text { otherwise } \\
\mathcal{H}_{i j}=H_{i j} \quad \text { if } j<i, \quad \mathcal{H}_{i j}=0 \quad \text { otherwise. }
\end{aligned}
$$

3. With this notation we rewrite (1.1)-(1.2) in the form

$$
\begin{gathered}
x_{i}=x(0)+\mathcal{A}_{10} x(0)+\sum_{j=1}^{\mu} \mathcal{A}_{i j} x_{j}+\mathcal{B}_{10} z(0)+\sum_{j=1}^{\mu} \mathcal{B}_{i j} z_{j}+\phi_{i}, \quad i=1, \ldots, \mu, \\
z_{i}=\mathcal{D}_{10} x(0)+\sum_{j=1}^{\mu} \mathcal{D}_{i j} x_{j}+\mathcal{H}_{10} z(0)+\sum_{j=1}^{\mu} \mathcal{H}_{i j} z_{j}+\psi_{i}, \quad i=1, \ldots, \mu,
\end{gathered}
$$

or

$$
\begin{gathered}
\left(\begin{array}{c}
x_{1} \\
\vdots \\
x_{\mu} \\
z_{1} \\
\vdots \\
z_{\mu}
\end{array}\right)=\left(\begin{array}{ccc}
E_{n}+\mathcal{A}_{10} & \mathcal{B}_{10} \\
\cdots & \cdots \\
E_{n}+\mathcal{A}_{\mu 0} & \mathcal{B}_{\mu 0} \\
\mathcal{D}_{10} & \mathcal{H}_{10} \\
\cdots & \cdots \\
\mathcal{D}_{\mu 0} & \mathcal{H}_{\mu 0}
\end{array}\right) \cdot\left(\begin{array}{c}
x(0) \\
z(0)
\end{array}\right)+ \\
+\left(\begin{array}{cccccc}
\mathcal{A}_{11} & \cdots & \mathcal{A}_{1 \mu} & \mathcal{B}_{11} & \cdots & \mathcal{B}_{1 \mu} \\
\cdots & \cdots & \cdots & \cdots & \cdots & \cdots \\
\mathcal{A}_{\mu 1} & \cdots & \mathcal{A}_{\mu \mu} & \mathcal{B}_{\mu 1} & \cdots & \mathcal{B}_{\mu \mu} \\
\mathcal{D}_{11} & \cdots & \mathcal{D}_{1 \mu} & \mathcal{H}_{11} & \cdots & \mathcal{H}_{1 \mu} \\
\cdots & \cdots & \cdots & \cdots & \cdots & \cdots \\
\mathcal{D}_{\mu 1} & \cdots & \mathcal{D}_{\mu \mu} & \mathcal{H}_{\mu 1} & \cdots & \mathcal{H}_{\mu \mu}
\end{array}\right) \cdot\left(\begin{array}{c}
x_{1} \\
\vdots \\
x_{\mu} \\
z_{1} \\
\vdots \\
z_{\mu}
\end{array}\right)+\left(\begin{array}{c}
\phi_{1} \\
\vdots \\
\phi_{\mu} \\
\psi_{1} \\
\vdots \\
\psi_{\mu}
\end{array}\right),
\end{gathered}
$$

where $E_{n}$ is the identity $(n \times n)$-matrix.

4. With the natural block form of the matrices we can write (2.1) as follows:

$$
\left(\begin{array}{c}
\mathbf{x} \\
z
\end{array}\right)=\left(\begin{array}{cc}
\mathcal{E}+\mathcal{A}_{0} & \mathcal{B}_{0} \\
\mathcal{D}_{0} & \mathcal{H}_{0}
\end{array}\right) \cdot\left(\begin{array}{c}
x(0) \\
z(0)
\end{array}\right)+\left(\begin{array}{cc}
\mathcal{A} & \mathcal{B} \\
\mathcal{D} & \mathcal{H}
\end{array}\right) \cdot\left(\begin{array}{c}
\mathbf{x} \\
z
\end{array}\right)+\left(\begin{array}{l}
\phi \\
\psi
\end{array}\right) .
$$

5. Let us continue the notation:

$$
\mathbf{P}=\left(\begin{array}{cc}
\mathcal{E}+\mathcal{A}_{0} & \mathcal{B}_{0} \\
\mathcal{D}_{0} & \mathcal{H}_{0}
\end{array}\right) ; \quad \mathbf{A}=\left(\begin{array}{cc}
\mathcal{A} & \mathcal{B} \\
\mathcal{D} & \mathcal{H}
\end{array}\right) ; \quad \mathbf{Q}=(\mathbf{E}-\mathbf{A})^{-1}
$$


It should be noted that the invertibility of $(\mathbf{E}-\mathbf{A})$ follows from its structure which is due to the construction given by the definition of the all elements. Moreover, the inverse $\mathrm{Q}$ is of the same structure. To illustrate this remark, we give an example for $n=2, \nu=1, \mu=3$ :

$$
\left(\begin{array}{ccccccccc}
1 & 0 & 0 & 0 & 0 & 0 & 0 & 0 & 0 \\
0 & 1 & 0 & 0 & 0 & 0 & 0 & 0 & 0 \\
\square & \square & 1 & 0 & 0 & 0 & \square & 0 & 0 \\
\square & \square & 0 & 1 & 0 & 0 & \square & 0 & 0 \\
\square & \square & \square & \square & 1 & 0 & \square & \square & 0 \\
\square & \square & \square & \square & 0 & 1 & \square & \square & 0 \\
0 & 0 & 0 & 0 & 0 & 0 & 1 & 0 & 0 \\
\square & \square & 0 & 0 & 0 & 0 & \square & 1 & 0 \\
\square & \square & \square & \square & 0 & 0 & \square & \square & 1
\end{array}\right),
$$

where $\square$ stands for a real number, all 1 and 0 are presented immediately.

6. Solving (2.2) with respect to $\operatorname{col}(\mathbf{x}, z)$, we obtain

$$
\left(\begin{array}{l}
\mathbf{x} \\
z
\end{array}\right)=\mathbf{Q P}\left(\begin{array}{c}
x(0) \\
z(0)
\end{array}\right)+\mathbf{Q}\left(\begin{array}{l}
\phi \\
\psi
\end{array}\right) .
$$

It is reasonable to note here that the first term in the right-hand side of (2.3) is responsible for the dependence of the solution on the initial state of the system and other describes the impact of the free term. We shall use (2.3) to give the final representation of the solution to (1.1)-(1.2). In doing so we denote by $\mathbf{Y}$ the product $\mathrm{QP}$ and employ for $\mathrm{Y}$ and $\mathrm{Q}$ the following block forms:

$$
\mathbf{Y}=\left(\begin{array}{cc}
Y_{11} & Y_{12} \\
Y_{21} & Y_{22}
\end{array}\right) ; \quad \mathbf{Q}=\left(\begin{array}{ll}
Q_{11} & Q_{12} \\
Q_{21} & Q_{22}
\end{array}\right)
$$

Thus we have

$$
\begin{aligned}
\mathbf{x} & =Y_{11} x(0)+Y_{12} z(0)+Q_{11} \phi+Q_{11} \psi, \\
z & =Y_{21} x(0)+Y_{22} z(0)+Q_{21} \phi+Q_{22} \psi
\end{aligned}
$$

and

$$
\begin{aligned}
& x_{j}=Y_{11}^{j} x(0)+Y_{12}^{j} z(0)+Q_{11}^{j} \phi+Q_{11}^{j} \psi, \quad j=1, \ldots, \mu, \\
& z_{j}=Y_{21}^{j} x(0)+Y_{22}^{j} z(0)+Q_{21}^{j} \phi+Q_{22}^{j} \psi, \quad j=1, \ldots, \mu,
\end{aligned}
$$

where $Y_{k 1}^{j}$ is the $j$-th group of $n$-rows to $Y_{k 1}, k=1,2$, and $Y_{k 2}^{j}$ is the $j$-th group of $\nu$-rows to $Y_{k 2}, k=1,2$. The matrices $Q_{k \ell}^{j}, k, \ell=1,2$, are defined in perfect analogy.

7. Note that (2.4) and (2.5) give the complete description for the component $z$ of the solution. As for $x$, let us recall that $x_{j}=x\left(t_{j}\right), j=1 \ldots, \mu$, and we need to get the representation of $x(t)$. To do this, we have to return to (1.1) and calculate $x(t)$ as $x(t)=x(0)+\int_{0}^{t} \dot{x}(s) d s$. Therewith we understand that $\dot{x}(s)$ should be replaced by the right-hand side of (1.1) with taking into account (2.6) and (2.7). To do this in a quite short form, we shall use the following notation:

$$
\mathcal{A}_{j}(t)=\int_{0}^{t} A_{j}(s) \chi_{j}(s) d s ; \quad \mathcal{B}_{j}(t)=\int_{0}^{t} B_{j}(s) \chi_{j}(s) d s ; \quad \phi(t)=\int_{0}^{t} f(s) d s .
$$


Thus we have

$$
\begin{aligned}
x(t)= & x(0)+\mathcal{A}_{0}(t) x(0)+\sum_{j=1}^{\mu} \mathcal{A}_{j}(t)\left[Y_{11}^{j} x(0)+Y_{12}^{j} z(0)\right]+\sum_{j=1}^{\mu} \mathcal{A}_{j}(t)\left[Q_{11}^{j} \phi+Q_{12}^{j} \psi\right]+ \\
& +\mathcal{B}_{0} z(0)+\sum_{j=1}^{\mu} \mathcal{B}_{j}(t)\left[Y_{21}^{j} x(0)+Y_{22}^{j} z(0)\right]+\sum_{j=1}^{\mu} \mathcal{B}_{j}(t)\left[Q_{21}^{j} \phi+Q_{22}^{j} \psi\right]+\phi(t),
\end{aligned}
$$

or

$$
\begin{aligned}
& x(t)= {\left[E_{n}+\mathcal{A}_{0}(t)+\sum_{j=1}^{\mu} \mathcal{A}_{j}(t) Y_{11}^{j}+\sum_{j=1}^{\mu} \mathcal{B}_{j}(t) Y_{21}^{j}\right] x(0)+} \\
&+ {\left[\mathcal{B}_{0}(t)+\sum_{j=1}^{\mu} \mathcal{A}_{j}(t) Y_{12}^{j}+\sum_{j=1}^{\mu} \mathcal{B}_{j}(t) Y_{22}^{j}\right] z(0)+} \\
&+\left[\sum_{j=1}^{\mu} \mathcal{A}_{j}(t) Q_{11}^{j}+\sum_{j=1}^{\mu} \mathcal{B}_{j}(t) Q_{21}^{j}\right] \phi+\phi(t)+\left[\sum_{j=1}^{\mu} \mathcal{A}_{j}(t) Q_{12}^{j}+\sum_{j=1}^{\mu} \mathcal{B}_{j}(t) Q_{22}^{j}\right] \psi
\end{aligned}
$$

For the component $z=\operatorname{col}\left(z_{1}, \ldots, z_{\mu}\right)$, we can rewrite (2.7) in the form

$$
z=Y_{21} x(0)+Y_{22} z(0)+Q_{21} \phi+Q_{22} \psi
$$

8. Therefore, for all components of (1.3), we obtain the following representations:

$$
\begin{gathered}
\mathcal{Y}_{11}=E_{n}+\mathcal{A}_{0}(t)+\sum_{j=1}^{\mu} \mathcal{A}_{j}(t) Y_{11}^{j}+\sum_{j=1}^{\mu} \mathcal{B}_{j}(t) Y_{21}^{j} \\
\mathcal{Y}_{12}=\mathcal{B}_{0}(t)+\sum_{j=1}^{\mu} \mathcal{A}_{j}(t) Y_{12}^{j}+\sum_{j=1}^{\mu} \mathcal{B}_{j}(t) Y_{22}^{j} ; \\
\mathcal{Y}_{21}=Y_{21} ; \quad \mathcal{Y}_{22}=Y_{22} ; \\
\left(\mathcal{C}_{11} f\right)(t)=\left[\sum_{j=1}^{\mu} \mathcal{A}_{j}(t) Q_{11}^{j}+\sum_{j=1}^{\mu} \mathcal{B}_{j}(t) Q_{21}^{j}\right] \phi+\int_{0}^{t} f(s) d s
\end{gathered}
$$

where $\phi=\operatorname{col}\left(\int_{0}^{t_{1}} f(s) d s, \ldots, \int_{0}^{t_{\mu}} f(s) d s\right)$.

Let us give this representation in a more explicit form:

$$
\left(\mathcal{C}_{11} f\right)(t)=\int_{0}^{t}\left\{E_{n}+\sum_{k=1}^{\mu}\left[\int_{s}^{t} \sum_{j=1}^{\mu}\left(A_{j}(\tau) Q_{11}^{j k}+B_{j}(\tau) Q_{21}^{j k}\right) \chi_{\left(t_{j}, T\right]}(\tau) d \tau\right] \chi_{\left[0, t_{k}\right]}(s)\right\} f(s) d s
$$

where $Q_{11}^{j k}$ is the $k$-th group of $n$-columns to $Q_{11}^{j}, Q_{21}^{j k}$ is the $k$-th group of $n$-columns to $Q_{21}^{j}$. The expression inside of $\{\cdots\}$ is the Cauchy matrix $C_{11}(t, s)$.

Next

$$
\left(\mathcal{C}_{12} g\right)(t)=\left[\sum_{j=1}^{\mu} \mathcal{A}_{j}(t) Q_{12}^{j}+\sum_{j=1}^{\mu} \mathcal{B}_{j}(t) Q_{22}^{j}\right] \psi
$$


where $\psi=\operatorname{col}\left(g\left(t_{1}\right), \ldots, g\left(t_{\mu}\right)\right)$; or, in a more explicit form,

$$
\left(\mathcal{C}_{12} g\right)(t)=\int_{0}^{t}\left\{\sum_{k=1}^{\mu}\left[\sum_{j=1}^{\mu}\left(A_{j}(s) Q_{12}^{j k}+B_{j}(s) Q_{22}^{j k}\right) \chi_{\left(t_{j}, T\right]}(s)\right] g\left(t_{j}\right)\right\} d s,
$$

where $Q_{12}^{j k}$ is the $k$-th group of $\nu$-columns to $Q_{12}^{j}, Q_{22}^{j k}$ is the $k$-th group of $\nu$-columns to $Q_{22}^{j}$.

$$
\mathcal{C}_{21} f=Q_{21} \operatorname{col}\left(\int_{0}^{t_{1}} f(s) d s, \ldots, \int_{0}^{t_{\mu}} f(s) d s\right), \quad \mathcal{C}_{22} g=Q_{22} \operatorname{col}\left(g\left(t_{1}\right), \ldots, g\left(t_{\mu}\right)\right) .
$$

Thus, we can formulate the main result.

Theorem 1. The general solution of the continuous-discrete system (1.1)-(1.2) has the representation (1.3) where $\mathcal{Y}_{i k}$ and $\mathcal{C}_{i k}, i, k=1,2$, are defined by the equalities (2.8)-(2.13).

\section{§3. An example}

Consider the system

$$
\begin{aligned}
\dot{x}(t) & =0.5 x(0)+0.5 \sin (t) \chi_{(1,4]}(t) x(1)+0.1 \exp (-0.1 t) \chi_{(2,4]}(t) x(2)+0.1 t^{2} \chi_{(3,4]}(t) x(3)+ \\
& +0.3 t z(0)+0.2 \chi_{(1,4]}(t) z(1)+0.1 t^{2} \chi_{(2,4]}(t) z(2)+0.15 \chi_{(3,4]}(t) z(3)+f(t), \quad t \in[0,4], \\
z(i)=0.4 x(0)+ & 0.5 \chi_{(1,4]}(i) x(1)+0.4 \chi_{(2,4]}(i) x(2)+0.3 \chi_{(3,4]}(i) x(3)+0.2 z(0)+ \\
& +0.2 \chi_{(1,4]}(i) z(1)+0.3 \chi_{(2,4]}(i) z(i)+0.15 \chi_{(3,4]}(i) z(3)+g(i), \quad i=1, \ldots, 4 .
\end{aligned}
$$

In this case, we have $\mathbf{A}=\left(\mathbf{A}_{1}, \mathbf{A}_{1}\right)$,

$$
\begin{array}{r}
\mathbf{A}_{\mathbf{1}}=\left(\begin{array}{cccc}
0 & 0 & 0 & 0 \\
0.708073418 & 0 & 0 & 0 \\
0.994996248 & 0.259181779 & 0 & 0 \\
0.826821810 & 0.329679954 & 2.133333333 & 0 \\
0 & 0 & 0 & 0 \\
0.5 & 0 & 0 & 0 \\
0 & 0 & 0 & 0 \\
0.5 & 0.4 & 0.3 & 0
\end{array}\right), \\
\mathbf{A}_{\mathbf{2}}=\left(\begin{array}{cccc}
0 & 0 & 0 & 0 \\
0.400000000 & 0 & 0 & 0 \\
0.600000000 & 0.899999999 & 0 & 0 \\
0.800000000 & 2.133333333 & 0.6000000000 & 0 \\
0 & 0 & 0 & 0 \\
0.2 & 0 & 0 & 0 \\
0 & 1 & 0 & 0 \\
0.2 & 0.3 & 0.4 & 0
\end{array}\right),
\end{array}
$$

$\mathbf{Q}=(\mathbf{E}-\mathbf{A})^{-1}=\left(\mathbf{Q}_{\mathbf{1}}, \mathbf{Q}_{\mathbf{1}}\right)$, 


$$
\begin{aligned}
\mathbf{Q}_{\mathbf{1}}= & \left(\begin{array}{cccc}
1 & 0 & 0 & 0 \\
0.708073418 & 1 & 0 & 0 \\
1.628515977 & 0.259181779 & 1 & 0 \\
6.161031126 & 1.122601083 & 2.133333333 & 1 \\
0 & 0 & 0 & 0 \\
0.500000000 & 0 & 0 & 0 \\
0.933229367 & 0.400000000 & 0 & 0 \\
1.795075907 & 0.637754534 & 0.300000000 & 0
\end{array}\right), \\
\mathbf{Q}_{\mathbf{2}}= & \left(\begin{array}{cccc}
0 & 0 & 0 & 0 \\
0.400000000 & 0 & 0 & 0 \\
0.883672712 & 0.899999999 & 0 & 0 \\
3.495707100 & 4.233333332 & 0.600000000 & 0 \\
1 & 0 & 0 & 0 \\
0.200000000 & 1 & 0 & 0 \\
0.420000000 & 0.300000000 & 1 & 0 \\
0.853101814 & 0.690000000 & 0.400000000 & 1
\end{array}\right),
\end{aligned}
$$

$$
\begin{aligned}
& \left(\mathcal{C}_{11} f\right)(t)=\int_{0}^{t}\{1+ \\
& +\int_{s}^{t}\left[0.5 \sin (\tau) \chi_{(1,4]}(\tau)+\left(0.050000000 \tau^{2}+0.0708073418 \exp (-0.1 \tau)\right) \chi_{(2,4]}(\tau)+\right. \\
& \left.\quad+\left(0.139984405+0.162851598 \tau^{2}\right) \chi_{(3,4]}(\tau)\right] \chi_{[0,1]}(s)+ \\
& +\left[0.1 \exp (-0.1 \tau) \chi_{(2,4]}(\tau)+\left(0.060000000+0.025918178 \tau^{2}\right) \chi_{(3,4]}(\tau)\right] \chi_{[0,2]}(s)+ \\
& \left.\quad+\left[0.1 \tau^{2} \chi_{(3,4]}(\tau)\right] \chi_{[0,3]}(s)\right\} d \tau f(s) d s
\end{aligned}
$$

$$
\begin{gathered}
\left(\mathcal{C}_{12} g\right)(t)=\int_{0}^{t}\left\{\left[0.2 \chi_{(1,4]}(s)+\left(0.040000000 \exp (-0.1 s)+0.020000000 s^{2}\right) \chi_{(2,4]}(s)+\right.\right. \\
\left.+\left(0.630000000+0.088367271 s^{2}\right) \chi_{(3,4]}(s)\right] g(1)+\left[0.100000000 s^{2} \chi_{(2,4]}(s)+\right. \\
\left.\left.+\left(0.045000000+0.089999999 s^{2}\right) \chi_{(3,4]}(s)\right] g(2)+\left[0.150000000 \chi_{(3,4]}(s)\right] g(3)\right\} d s
\end{gathered}
$$

$$
\begin{aligned}
& \mathcal{C}_{21} f=\left(\begin{array}{l}
0 \\
0.5 \int_{0}^{1} f(s) d s \\
0.933229367 \int_{0}^{1} f(s) d s+0.4 \int_{0}^{2} f(s) d s \\
1.795075907 \int_{0}^{1} f(s) d s+0.637754534 \int_{0}^{2} f(s) d s+0.300000000 \int_{0}^{3} f(s) d s
\end{array}\right), \\
& \mathcal{C}_{22} g=\left(\begin{array}{l}
g(1) \\
0.2 g(1)+1 g(2) \\
0.420000000 g(1)+0.3 g(2)+1 g(3) \\
0.853101814 g(1)+0.690000000 g(2)+0.4 g(3)+1 g(4)
\end{array}\right) .
\end{aligned}
$$

All results of calculations are displayed to the ninth decimal place. 


\section{$\S 4$. Conclusive remarks}

In conclusion it should be noted that a more general case of (1.1) with a Volterra functional differential operator $\mathcal{L}: A C^{n}[0, T] \rightarrow L^{n}[0, T]$ instead of $d / d t$ in the left-hand side can be reduced to (1.1) if $\mathcal{L}$ has the Cauchy matrix $C(t, s)$ [4]. Namely, let us recall that the general solution to $\mathcal{L} x=r$ has the representation

$$
x(t)=X(t) \alpha+\int_{0}^{t} C(t, s) r(s) d s
$$

and we have

$$
\dot{x}(t)=\dot{X}(t) \alpha+\int_{0}^{t} C_{t}^{\prime}(t, s) r(s) d s+r(t) .
$$

As applied to

$$
(\mathcal{L} x)(t)=\sum_{j: t_{j}<t} A_{j}(t) x\left(t_{j}\right)+\sum_{j: t_{j}<t} B_{j}(t) z\left(t_{j}\right)+f(t), t \in[0, T],
$$

(4.2) means that (4.3) can be rewritten in the form

$$
\dot{x}(t)=\sum_{j: t_{j}<t} \hat{A}_{j}(t) x\left(t_{j}\right)+\sum_{j: t_{j}<t} \hat{B}_{j}(t) z\left(t_{j}\right)+\hat{f}(t), t \in[0, T],
$$

where the new coefficients $\hat{A}_{j}(t), \hat{B}_{j}(t)$ and the new free term $\hat{f}(t)$ are calculated with the use of $C_{t}^{\prime}(t, s)$ and $\dot{X}(t)$.

Thus the Cauchy matrix takes the responsibility for the memory of $\mathcal{L}$ and the new discrete memory in (4.4). The complete description of a class of operators with the Cauchy matrix such that (4.2) follows from (4.1) is given in [4].

Funding. The research was supported by the Russian Foundation for Basic Research (project no. 18-01-00332).

\section{REFERENCES}

1. Agranovich G. A. Some problems of discrete/continuous systems stabilization, Functional Differential Equations, 2003, vol. 10, no. 1-2, pp. 5-17. https ://zbmath.org/?q=an:1175.93185

2. Agranovich G. A. Observability criteria of linear discrete-continuous system, Functional Differential Equations, 2009, vol. 16, no. 1, pp. 35-51. https : // zbmath.org/?q=an:1172 . 93010

3. Chadov A. L., Maksimov V.P. Linear boundary value problems and control problems for a class of functional differential equations with continuous and discrete times, Functional Differential Equations, 2012, vol. 19, no. 1-2, pp. 49-62. https: / / zbmath.org/?q=an:1322 . 34077

4. Maksimov V.P. The Cauchy formula for a functional differential equation, Differentsial'nye Uravneniya, 1977, vol. 13, no. 4, pp. 601-606 (in Russian). http://mi .mathnet.ru/eng/de3033

5. Maksimov V.P. On a linear optimal control problem for functional differential systems with continuous and discrete times, Functional Differential Equations: Theory and Applications: Proceedings of Conference Dedicated to the 95th Birthday Anniversary of Professor N. V. Azbelev, Perm National Research Polytechnic University, Perm, 2018, pp. 134-141 (in Russian). https: / /elibrary.ru/item.asp?id=35107826

6. Maksimov V.P. On a class of optimal control problems for functional differential systems, Proceedings of the Steklov Institute of Mathematics, 2019, vol. 305, suppl. 1, pp. 114-124.

https://doi.org/10.1134/s0081543819040126 
7. Maksimov V.P. Reliable computing experiment in the study of functional-differential equations: theory and applications, Journal of Mathematical Sciences, 2018, vol. 230, no. 5, pp. 712-716. https://doi.org/10.1007/s10958-018-3775-3

8. Maksimov V.P. The structure of the Cauchy operator to a linear continuous-discrete functional differential system with aftereffect and some properties of its components, Vestnik Udmurtskogo Universiteta. Matematika. Mekhanika. Komp'yuternye Nauki, 2019, vol. 29, issue 1, pp. 40-51. https://doi.org/10.20537/vm190104

9. Maksimov V.P. Attainable values of on-target functionals in economic dynamic problems, Prikladnaya Matematika i Voprosy Upravleniya, 2019, no. 4, pp. 124-135 (in Russian). https: / /www.elibrary.ru/item.asp?id=41863871

10. Marchenko V. M. Hybrid discrete-continuous systems with control: II. State space method, Differential Equations, 2015, vol. 51, no. 1, pp. 54-68. https://doi.org/10.1134/s0012266115010061

11. Marchenko V.M. Controllability and observability of hybrid discrete-continuous systems in the simplest function classes, Differential Equations, 2015, vol. 51, no. 11, pp. 1461-1475. https://doi.org/10.1134/S0012266115110075

12. Marchenko V. M. Modal control of hybrid differential-difference systems and associated delay systems of neutral type in scales of differential-difference controllers, Differential Equations, 2017, vol. 53, no. 11, pp. 1458-1474. https://doi.org/10.1134/S0012266117110088

13. Simonov P. M. On a method of the study of macroeconomics dynamic models, Vestnik Permskogo Universiteta. Ser. Ekonomika, 2014, no. 1, pp. 14-27 (in Russian).

https://elibrary.ru/item.asp?id=21372381

Received 17.05.2020

Maksimov Vladimir Petrovich, Doctor of Physics and Mathematics, Professor, Department of Information Systems and Mathematical Methods in Economics, Perm State National Research University, ul. Bukireva, 15, Perm, 614990, Russia.

E-mail: maksimov@econ.psu.ru

Citation: V.P. Maksimov. On a class of linear continuous-discrete systems with discrete memory, Vestnik Udmurtskogo Universiteta. Matematika. Mekhanika. Komp'yuternye Nauki, 2020, vol. 30, issue 3, pp. 385-395. 


\section{В. П. Максимов}

\section{Об одном классе линейных непрерывно-дискретных систем с дискретной памятью}

Ключевые слова: линейные системы с последействием, непрерывно-дискретные функциональнодифференциальные системы, представление решений, оператор Коши.

УдК 517.929

DOI: $10.35634 / \mathrm{vm} 200303$

В статье рассматривается класс линейных систем функционально-дифференциальных уравнений с непрерывным и дискретным временем и дискретной памятью. В рамках этого класса предлагается явное представление для основных составляющих представления общего решения - фундаментальной матрицы и оператора Коши. Полученные представления даются в терминах параметров рассматриваемой системы и открывают возможность эффективного исследования общих краевых задач и задач управления относительно заданной конечной системы линейных целевых функционалов. При исследовании упомянутых задач для систем за пределами изучаемого класса рассматриваемые в работе системы с дискретной памятью могут играть роль модельных или аппроксимирующих систем и оказаться полезными при изучении грубых свойств систем с последействием, сохраняющихся при малых возмущениях параметров.

Финансирование. Работа поддержана Российским фондом фундаментальных исследований, проект № 18-01-00332.

\section{СПИСОК ЛИТЕРАТУРЫ}

1. Agranovich G. A. Some problems of discrete/continuous systems stabilization // Functional Differential Equations. 2003. Vol. 10. No. 1-2. P. 5-17. https://zbmath.org/?q=an:1175.93185

2. Agranovich G. A. Observability criteria of linear discrete-continuous system // Functional Differential Equations. 2009. Vol. 16. No. 1. P. 35-51. https : //zbmath.org/?q=an:1172 . 93010

3. Chadov A.L., Maksimov V.P. Linear boundary value problems and control problems for a class of functional differential equations with continuous and discrete times // Functional Differential Equations. 2012. Vol. 19. No. 1-2. P. 49-62.

https://elibrary.ru/item.asp?id=22291874

4. Максимов В. П. О формуле Коши для функционально-дифференциального уравнения // Дифференциальные уравнения. 1977. Т. 13. № 4. С. 601-606. http://mi.mathnet.ru/de3033

5. Максимов В.П. О линейной задаче оптимального управления для функционально-дифференциальных систем с непрерывным и дискретным временем // Функционально-дифференциальные уравнения: теория и приложения. Материалы конференции, посвященной 95-летию со дня рождения профессора Н. В. Азбелева, Пермь, 17-19 мая 2017. Перм. нац. исслед. политех. ун-т., Пермь, 2018. C. 134-141. https://elibrary.ru/item.asp?id=35107826

6. Максимов В.П. Об одном классе задач оптимального управления для функционально-дифференциальных систем // Труды Института математики и механики УрО РАН. 2018. Т. 24. № 1. C. 131-142. https://doi.org/10.21538/0134-4889-2018-24-1-131-142

7. Maksimov V.P. Reliable computing experiment in the study of functional-differential equations: theory and applications // Journal of Mathematical Sciences. 2018. Vol. 230. No. 5. P. 712-716. https://doi.org/10.1007/s10958-018-3775-3

8. Maksimov V.P. The structure of the Cauchy operator to a linear continuous-discrete functional differential system with aftereffect and some properties of its components // Вестник Удмуртского университета. Математика. Механика. Компьютерные науки. 2019. Т. 29. Вып. 1. С. 40-51. https://doi.org/10.20537/vm190104

9. Максимов В.П. Достижимые значения целевых функционалов в задачах экономической динамики // Прикладная математика и вопросы управления. 2019. № 4. С. 124-135.

https://www.elibrary.ru/item.asp?id=41863871 
10. Марченко В.М. Гибридные дискретно-непрерывные системы с управлением. II. Метод пространства состояний // Дифференциальные уравнения. 2015. Т. 51. № 1. С. 55-69. https://doi.org/10.1134/S0374064115010069

11. Марченко В. М. Управляемость и наблюдаемость гибридных дискретно-непрерывных систем в простейших классах функций // Дифференциальные уравнения. 2015. Т. 51. № 11. С. 1469-1481. https://doi.org/10.1134/S0374064115110072

12. Марченко В. М. Модальное управление гибридными дифференциально-разностными системами и ассоциированными системами с запаздывающим аргументом нейтрального типа в шкалах дифференциально-разностных регуляторов // Дифференциальные уравнения. 2017. Т. 53. № 11 . C. 1491-1506. https://doi.org/10.1134/S0374064117110085

13. Симонов П. М. Об одном методе исследования динамических моделей макроэкономики // Вестник Пермского университета. Сер. Экономика. 2014. № 1 (20). С. 14-27. https://elibrary.ru/item.asp?id=21372381

Поступила в редакцию 17.05 .2020

Максимов Владимир Петрович, д. ф.-м. н., профессор, кафедра информационных систем и математических методов в экономике, Пермский государственный национальный исследовательский университет, 614990, Россия, г. Пермь, ул. Букирева, 15.

E-mail:maksimov@econ.psu.ru

Цитирование: В. П. Максимов. Об одном классе линейных непрерывно-дискретных систем с дискретной памятью // Вестник Удмуртского университета. Математика. Механика. Компьютерные науки. 2020. Т. 30. Вып. 3. С. 385-395. 